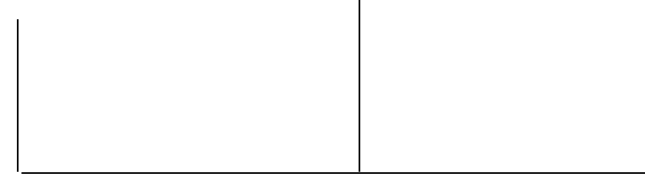

Rev. Latinoam. Psicopat. Fund., IV, 3, 116-121

\title{
Ele não quer? Nem eu!
}

\author{
Cassandra Pereira França
}

Vem, morte, mas escondida o bastante para que não te sinta chegar ... porque o prazer de morrer poderia me trazer de novo à vida.

Salvador Dalí

\section{O impasse}

O telefone toca e, do outro lado, uma voz angustiada faz um apelo desesperado: que aceitemos conversar com um filho com quem não se sabe mais o que fazer. A amargura invade a rotina familiar, corroída por tentativas de aproximação afetiva de alguém que mais parece um autômato, um corpo esvaziado de emoções. Da alegria da convivência de tempos atrás, restaram apenas lembranças que machucam, justamente por contrastarem tanto com o ódio de si e de todos de que foi tomado aquele adolescente, que, agora em estado de prontidão bélica, vigia dia e noite o "inimigo", sequer podendo dormir. A vigília constante só é vencida pela exaustão do corpo, que faz latejar a cabeça e aumentar a indisposição de falar com quem quer que seja. 
Do lado de cá da linha telefônica, arriscamos uma pergunta, cuja resposta, óbvia, criará o impasse: “Ele quer ser atendido?” A negativa esperada não consegue evitar uma medida defensiva do nosso aparelho psíquico, perceptível na tentação de dizer: “Ele não quer? Nem eu!” Razões conscientes para justificar tal posição, sustentadas principalmente pela teoria da técnica psicanalítica, não nos faltam - a começar pelo fato de que a demanda, apesar de procedente, não partiu do sujeito, e não há como dispensar um comprometimento interno forte para um trabalho de escuta do inconsciente. Além do mais, em tais casos, até que o analista obtenha a confiança do cliente, sua função se resumirá à de "pára-raios”, que receberá toda a descarga energética de destrutividade da qual o sujeito está tomado. Função nada agradável para qualquer um de nós, mas de cujo manejo dependerá o sucesso da empreitada, pois, se suportarmos a hostilidade daquele jovem, sem nos abalarmos com os efeitos das identificações projetivas excessivas, e transformarmos os conteúdos projetados em elementos pensáveis, poderemos receber, cada vez mais, outros conteúdos representacionais.

Todo aquele que tem prática clínica com adolescentes sabe que as contingências relativas a situações como a descrita fazem com que a proposta dos pais ecoe como um convite para que entremos na "jaula do leão". A decisão de entrar estará diretamente relacionada a experiências anteriores: se não as temos, falta-nos a cautela necessária para declinarmos do convite; se as temos e sobrevivemos a elas, conseguindo ajudar o paciente, julgamos que o desafio valeu a pena. Mas, seja por razões transferenciais ou contratransferenciais, graças à mobilização do mundo interno do analista, o impasse se mantém: como atender alguém que está irrascível e cuja demanda, tal como na psicose, não partiu de si próprio, e sim do campo social?

\section{Algumas alternativas possíveis}

Quando o adolescente aceita ficar no mesmo ambiente que os pais e irmãos, podemos propor, a priori, como alternativa, o atendimento familiar. Mas se o indivíduo não estiver suportando o convívio com as pessoas da casa, seria pedir demais que ele comparecesse àquilo que, imaginariamente, não passaria de mera repetição do julgamento de um condenado. Convidar os pais para algumas entrevistas iniciais não deixa de ser sensato, mas há o risco de inviabilizar-se um processo psicoterápico futuro, uma vez que o adolescente não hesitará em crer que conspiramos contra ele, já que pertencemos à mesma tribo dos pais, ou seja, a dos adultos, de quem, aliás, receberemos nossos honorários. Acresça-se a possibilidade de, ao se encontrarem, analista e adolescente terem sua comunicação perturbada pelas emoções do par parental, que, emaranhadas no campo transferencial, poderão ter sido projetadas no analista, deixando-o vulnerável a elas. Configura-se, aqui, um campo 
minado no qual se pisa sob o comando de uma intuição que, mesmo feliz, apenas nos garantirá o próximo passo.

Em vários casos extremados com que tive de me haver, optei por dar como passo inicial o estabelecimento, junto à família, de pré-condições para atender esses adolescentes, tais como a de ficar "a sós" com eles durante muitos meses, até ser construído um vínculo transferencial capaz de suportar a entrada da família no processo, ocasião em que os pais serão convidados a participar das sessões do filho. Esse pacto, via de regra, costuma ser respeitado, a menos que haja alguma atuação do paciente que justifique uma precipitação do processo, quando, então, é solicitada a vinda dos pais, ou a entrada em cena da assistência psiquiátrica. O contrato terapêutico, portanto, acabará sendo feito diretamente com o adolescente e deverá ter uma dosagem de flexibilidade tal que permita ao paciente experienciar o processo por algum tempo, antes de decidir-se por interrompê-lo ou prosseguir - decisão que receberá o nosso apoio integral, inclusive diante da família.

\section{As concessões}

Para o analista, sem dúvida alguma, é vantajoso dar-se a conhecer aos pais e deles receber aprovação para cuidar de seu filho: uma empatia poderá auxiliar não apenas a estruturação do vínculo transferencial dos pais, como também torná-lo, futuramente, sustentáculo do vínculo transferencial do próprio filho com o analista. Além do mais, as entrevistas com os pais são momentos preciosos em que se desfazem fantasias acerca do tratamento e formulam-se pedidos de ajuda para si próprios; constituem-se, assim, oportunidades ímpares para a observação da dinâmica do relacionamento do casal e das modalidades usuais de triangulação com os filhos. É por todos esses motivos que usualmente recebemos os adolescentes junto a seus pais e os deixamos à vontade para nos procurarem quando quiserem, embora fique claro que deverão marcar com certa antecedência sua vinda, que não prescindirá da anuência do filho e de sua presença na sessão: não podemos nos esquecer de quão desconfiados são os adolescentes. Porém, se tivermos de ficar privados, temporariamente, desses contatos, devemos estar cientes do risco de que tal contingência, por si só, estimule atuações dos pais e até a retirada do filho do tratamento.

É desse modo que, mesmo sem o saber, esse jovem, então fora dos trilhos da "normalidade" da adolescência, que não pode abrir a guarda, nem por um momento, frente aos adultos que o cercam, acaba impondo a circulação de valiosas concessões: de seu lado, a de comparecer ao consultório; por parte dos pais, a de não comparecerem; no que respeita ao analista, a de sair da posição confortável de manter sua atenção flutuante e aguardar as associações livres. 
Concessões que acabam requerendo um manejo técnico distinto das práticas convencionais de atendimento a adolescentes, e que se transformam numa combinação delicada que merece algumas considerações. Se, por força das circunstâncias, os pais concordarem em adiar o relato daqueles fatos que os angustiam, em protelar as recomendações sobre as condutas que desejam ver alteradas e, acima de tudo, em retardar a verificação, com seus próprios olhos, das condições psíquicas do analista de lhes prestar algum auxílio, é porque a situação chegou às raias do insustentável - sinal de que podemos esperar chuvas e trovoadas dentro do setting analítico. Efeitos que se apresentarão inicialmente sob a forma de respostas monossilábicas, devolvidas sem qualquer elaboração, às perguntas esparsas que arriscamos fazer ao adolescente, para quebrar os longos silêncios de resistência, e que farão com que a sensação de impotência domine o analista nos primeiros tempos. E se, por acaso, algum progresso for alcançado, haverá sempre o risco de que, na próxima sessão, ele se desvaneça e, tal como no tratamento dos psicóticos, o processo retorne à estaca zero. Aliás, a pertinência das intervenções do analista, por exigirem da parte do cliente uma reconsideração da validade do processo, podem gerar as reações mais adversas, que vão de silêncios paralisantes a saídas abruptas do consultório, ou, ainda, à reinstalação de uma postura de indiferença ou de ódio fulminante em relação ao analista. Reações que podem ter intensidade suficiente para gerar no analista uma atitude mental, antes da entrada do cliente, semelhante à dos nadadores profissionais que, em respeito à força das águas, fazem o sinal da cruz antes de se atirarem ao mar.

Afinal de contas, por que tantos escrúpulos? Porque estamos lidando com pessoas que têm a vulnerabilidade de "esfolados vivos" e que precisam fechar-se numa redoma narcísica para suportarem a dor existencial. Assim sendo, terão, naturalmente, de reagir mal à nossa entrada em seu mundo interno, em sua intimidade, não hesitando em provar, com virulência, que pensamentos são privativos e que não devem ser partilhados. Máxima que se choca frontalmente com os propósitos do analista, uma vez que, como já se falou, quando clinicamos nos metemos na história que o sujeito conta de si. Arranhões à parte, espera-se que o analista tenha conseguido, a partir de sua análise pessoal, desenvolver sua capacidade de conter tais ataques, podendo prosseguir seu trabalho movido pelo desejo de retirar os entraves resistenciais que impedem aquele paciente de contar e recontar sua história, até que entenda por que recuou diante do convite de girar com o mundo.

\section{O processo melancólico}

Em um primeiro momento, poderíamos julgar que a grande agressividade descrita denunciaria apenas uma revolta diante das perdas sofridas - dentre elas, o papel e o corpo de criança e, sobretudo, os pais idealizados da infância - , vivências 
presentes em diferentes intensidades nos adolescentes e que refletem o modo como puderam lidar com perdas no passado. Notícias desses tempos chegam-nos através de palavras fortuitas que inadvertidamente revelam quão difícil foi, nesses casos, tomar alguma distância do objeto primário: "Eu era tão grudado na minha mãe que sou capaz de sentir ainda o ardor dos pingos de gordura que saltavam do fogão, enquanto ela cozinhava!” Imagem que nos permite entender por que a mãe está obliterada do discurso do sujeito: justamente por encontrar-se tão próxima dele, tão colada.

O reflexo desse estado fusional com a mãe recai na montagem da estrutura relacional e na escolha da namorada: "Eu gosto que ela me trate como se fosse minha mãe!” Desejo que destoa da aparente indiferença para com a mãe da realidade, que não parece fazer falta sequer como alvo para os ataques de ódio do cliente. No entanto, quando visto mais de perto, o namoro ilustra o modo como uma relação objetal pode, facilmente, transformar-se numa sujeição cega ao objeto - desde que este se preste à reedição da ilusão de que o objeto primário não está perdido. Enquanto houver esse objeto que possa validar essa ilusão e suportar a agressividade defletida, haverá um equilíbrio pulsional, precário, mas capaz de manter o indivíduo vivo. Contudo, se o objeto se rebelar e sair do único lugar que lhe é concedido, o retorno da catexia objetal fará com que a hostilidade, que representa a reação original do ego para com os objetos do mundo externo, seja dirigida contra o próprio indivíduo. Redirecionado para o ego, o sadismo tentará arrastar o sujeito para a morte, por meio de repetidas tentativas de suicídio.

O evitamento das relações afetivas, perfeitamente compreensível nesses casos de escolha objetal efetuada em bases narcisistas, pode camuflar-se em contatos humanos via Internet; ou manifestar-se claramente em palavras como: "Eu só posso vir aqui de vez em quando, porque não posso descobrir que dependo de você!” Pacientes nesse estado sentem-se impedidos de qualquer contato mais íntimo com o analista, temendo ser assujeitados ou, mesmo, atacados por ele com pensamentos humilhantes. Receber ajuda supõe fraqueza, que é sentida como um fracasso pela organização narcísica destrutiva que abastece o paciente com seu senso de superioridade.

Evidências paralelas, como a falta de interesse pelo mundo, a diminuição da auto-estima, a insônia, bem como a presença das três pré-condições estabelecidas por Freud em "Luto e melancolia” (1917), quais sejam, a perda do objeto, a ambivalência e a regressão da libido ao ego, levantam a possibilidade de estarmos diante de quadros de melancolia, instalados devido a uma disposição patológica narcísica, que impediu o indivíduo de dar prosseguimento à constituição de sua subjetividade e não o preparou para enfrentar as sucessivas angústias castrativas, que se arrastariam ao longo da vida.

O paciente, contudo, vai percebendo, gradualmente, que está sendo dominado por uma parte infantil, onipotente, que não só o infantiliza e impede de crescer, mas 
também o empurra em direção à morte. Acaba reconhecendo que seu corpo não colabora com o desejo de se manter eternamente criança, suas formas adultas pedem uma elaboração do luto do corpo perdido e prometem outros prazeres, mais gratificantes. Está cansado de brigar com o mundo, algumas pessoas são interessantes ... o analista é mais próximo, mais simples e muito menos perigoso do que imaginava e, talvez, até tenha sido um adolescente feliz. Está quase descobrindo que a melhor política doméstica não é a da queda de braços: “Não recuei, apenas atenuei!” Diante dessa pequena abertura, respiro aliviada por não ter respondido impulsivamente àquela pergunta inicial, e por ter sustentado, silenciosamente, uma atitude que corresponderia a uma outra resposta: "Ele não quer? Pois que pelo menos me dê a chance de, por algum tempo, querer por nós dois!”

\section{Referências bibliográficas}

Bleichmar, Hugo. O narcisismo: estudo sobre a enunciação e a gramática do inconsciente. Porto Alegre: Artes Médicas, 1985.

Cassorla, Roosevelt M. S. No emaranhado de identificações projetivas cruzadas com adolescentes e seus pais. In Revista Brasileira de Psicanálise, 31: 3, 1997.

FREUD, Sigmund (1917[1915]). Luto e melancolia. E.S.B. Rio de Janeiro: Imago, 1980. v. XIV.

GreEn, André. Narcisismo de vida, narcisismo de morte. São Paulo: Escuta, 1988.

Versão inicial recebida em novembro de 2000

Versão revisada recebida em julho de 2001 